\title{
Coupling of Modelica and Biochemical Simulator, SUMO, by Using C-API
}

\author{
Satomi Nishida ${ }^{1}$ Takayuki Ohtsuki ${ }^{2}$ \\ ${ }^{1}$ Modelon KK, Japan, satomi .nishida@modelon. com \\ ${ }^{2}$ Kurita Water Industries Ltd., Japan, t . ootsuki32@kurita-water.com
}

\begin{abstract}
Wastewater treatment engineering field has its own domain specific simulation needs and especially for the biological treatment process, which is the main process of municipal wastewater treatment, large scale dynamic models have been heavily used since the late 80's along with its specific model description method. However, most of wastewater treatment process simulators focus on modelling of the treatment reaction performance of the treatment process units involved and lacks capability to analyze related mechanical components such as valves, pumps and blowers in detail. On the other hand, need for mechanical component performance analysis has been growing from the cost management perspective, for example, minimization of electric energy consumption and maintenance interval estimation because a large part of these cost happens at the mechanical components in the system. Operation improvement should be achieved without deterioration of the treated effluent water quality, therefore, the simulator coupling based on system analysis approach utilizing existing process models and Modelica based mechanical component models can be promising option.

This paper reports the results of coupled simulation framework development for a biological wastewater process simulator, SUMO, and Modelica. Biological treatment process and its related mechanical components were simulated by SUMO and Modelica, respectively. Dynamic simulation was conducted to evaluate the influence of controller parameter settings for the aeration system in a specific biological process. Specifically, the impact on the effluent quality, on the electric energy consumption and on the cycle frequency of the air flow control valves. It was also demonstrated that Modelica can be used with domain specific models for industries where Modelica and related model interface technology like FMI is not common, as far as such domain simulator supports a simple low-level C language interface.
\end{abstract}

Keywords: Modelica, SUMO, Wastewater Treatment, Biological process, Simulator coupling, C-API

\section{Introduction}

Main focus of wastewater treatment system is always effluent water quality stability, and it requires keeping some allowance on operation conditions to meet influent wastewater load fluctuation which is the main cause of the system disturbance for the treatment system; this way of system management often causes energy and cost loss. On the other hand, recent days even in the wastewater treatment field, energy reduction and cost reduction are gaining more attention and this situation requires operation management that takes into account energy consumption reduction as well as water quality stability. Energy consumption in such process happens typically at mechanical systems attached to the water treatment process such as pumps and blowers. This is the main motivation to conduct system simulations that allow analysis of the biological process and mechanical component performance simultaneously.

Although a number of simulators for chemical and biochemical processes are used in the water treatment process industry, they often lack capabilities to analyze the performance of mechanical components used. Modelica could be one of choices for such mechanical component simulation, however, technologies of Modelica and FMI are not widely used in the water treatment process industries at this moment.

SUMO is a commonly used simulator for biological wastewater treatment. It has a $\mathrm{C}$ language interface called C-API and can be invoked from Modelica by using External Object.

In this paper, a biological wastewater treatment system was modeled. A simulator coupling framework was implemented using the C-API. The case study with various conditions was conducted, and the effect of conditions on both the biological process and the mechanical component operation was evaluated. Dymola (Dassault Systems) is used as our Modelica platform. 


\section{Water Treatment Background}

\subsection{Overview}

Water treatment processes are mainly classified into physicochemical methods and biological methods (Sperling and Chernicharo, 2005). Physicochemical methods separate pollutants by size, specific gravity, and chemical characteristics, e.g. sedimentation and filtration. Biological methods treat water by using the absorption and decomposition by microorganisms, e.g. aerobic activated sludge process and anaerobic digestion process.

Biological wastewater treatment processes are commonly used for decomposition of organic pollutants. The adaptability of biological consortia to wide range of organic contaminants and the high energy efficiency of biological catalytic reactions have made it a main treatment process in municipal wastewater treatment processes and also in industries which generate organic wastewater. Aerobic wastewater treatment processes require oxygen for microorganism activity, and blowers to supply air consume most of the electric energy of the treatment process.

Wastewater treatment systems for industries are generally composed of various types of water treatment processes to achieve certain level of effluent quality. But still the biological wastewater treatment process is the key process for organic contaminant removal. And its blower is known to be the main energy consumer of the system. This report focused on a Moving Bed

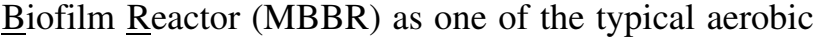
activated sludge biological treatment processes used in industry.

\subsection{Moving Bed Biofilm Reactor System}

An MBBR was originally developed by Kaldnes Miljøteknologi. It consists of aeration tanks with moving media where biofilm grows. The media are continuously moved by vigorous liquid flow driven by aeration (Sidek et al., 2016). MBBR is widely used for various wastewater treatment mainly because it allows one pass treatment which makes its operation easier compared to conventional suspended growth type activated sludge system without internal media which requires sludge return to keep sufficient biomass concentration in its main reactors. On the other hand, it is also known that the oxygen dissolution efficiency of MBBR is inferior to that of conventional activated sludge process because the media enhances coalescence phenomena of microbubbles injected by blowers and air diffusers which effectively reduces the surface area for the oxygen gas transfer to liquid phase. The electric energy consumption for aeration of MBBR becomes larger due to this poor oxygen dissolution efficiency. Therefore, especially in an MBBR process, aeration control strategy is important to minimize this larger energy requirement.
Figure 1 shows the example configuration of an MBBR system, which is modeled in this report. This system has three reactors, A, B and C. Wastewater is supplied to the tanks A and B equally, and then cascades into the tank $\mathrm{C}$ with an expectation of polishing effect. The header pipe pressure is kept constant by controlling the blower motor rotation speed through an inverter. Dissolved oxygen (DO) concentration sensors are installed at each tank. The airflow to the tanks A and B is controlled by multiple on/off valves to keep DO concentration at its target value. Air flow to the reactor $\mathrm{C}$ is kept almost constant.

To supply air to the reactors, MBBR is equipped with aeration unit. This example configuration has several Roots-type blowers. Each blower is equipped with an inverter, and the blower outlet pressure is kept constant by the blower speed control. If the outlet pressure becomes too high or low because of excessive or insufficient air flow at the minimum or maximum blower speed, the number of blowers running is reduced or increased by the on/off controller.

\subsection{SUMO}

Dynamic simulation models of biological processes in the wastewater treatment domain have been widely used since 1987 when the mathematical modelling task group of International Water Association (IWA formally called as IAWPRC) proposed a general base framework of activated sludge process model called ASM1 (Henze et al., 1987). The wastewater treatment process is inherently dynamic as the influent to the treatment system is always fluctuating and the biological consortia, usually called as activated sludge in this domain, is adapting to changing conditions. Therefore, the process model needs to be dynamic. This model has been expanded and enhanced by the task group as ASM2, ASM2d and ASM3 (Henze et al., 2000). The first commercial implementation of these model and their enhanced models named GPS (and soon after its successor GPS-X) were put into market around 1989 (Patry and Chapman, 1989).

SUMO is a relatively new platform for wastewater treatment modelling and simulation (Russell, 2019), which is fundamentally based on ASM model concepts, but vastly expands the model scope to cover much more detailed biological reactions, ionic species equilibrium for $\mathrm{pH}$ estimation and gas transfer phenomena typically linked with aeration system. The supported unit process models include the conventional suspended growth activated sludge system and other wide variety of biofilm processes including MBBR. It supports both dynamic and steady-state simulations.

Some of the commercial implementations of these models use a tabular model description format called Gujer matrix, introduced by Henze et al. (1987) for the explanation of biokinetic reaction models. This format is now widely accepted as one of the standard methods 
of representing biokinetic models by research communities (Rieger et al., 2012). SUMO extends this tabular model representation format. Proprietary model description language called SumoSlang (Kovács et al., 2013) has a highly optimized syntax for the specific needs of water treatment process model descriptions in couple of table formats. Not only biokinetic reactions, but also equilibrium chemistry equations and algebraic declarative models are expressed in a two-dimensional table format in Excel. These models are automatically translated into $\mathrm{C}++$ programs by the custom lexical analyzer and parser which use Excel model descriptions as source codes, and these $\mathrm{C}++$ programs are further linked to customized initial steady-state solver and DAE solver settings. In the biological treatment domain, many modelers find this Gujer-matrix type format easy to understand, which is one of the reasons why they do not use general simulation languages such as Modelica. These features of the model description make SUMO and other wastewater simulators alike unique as domain-oriented simulation system which is quite different from the generic nature of Modelica.

There is a Modelica library (Reichl, 2003) of original models of ASM series, which is a part of the scope of SUMO. However, they have not been maintained to cover the latest biological model enhancements, and it is generally assumed that their model implementations are not easy to understand for modelers in the water treatment industry without the familiar Gujer matrix type tabular model representations. In the author's opinion, this is one of the main reasons why generic simulation languages are not so popular in the water treatment industry, especially in biological treatment engineering fields.

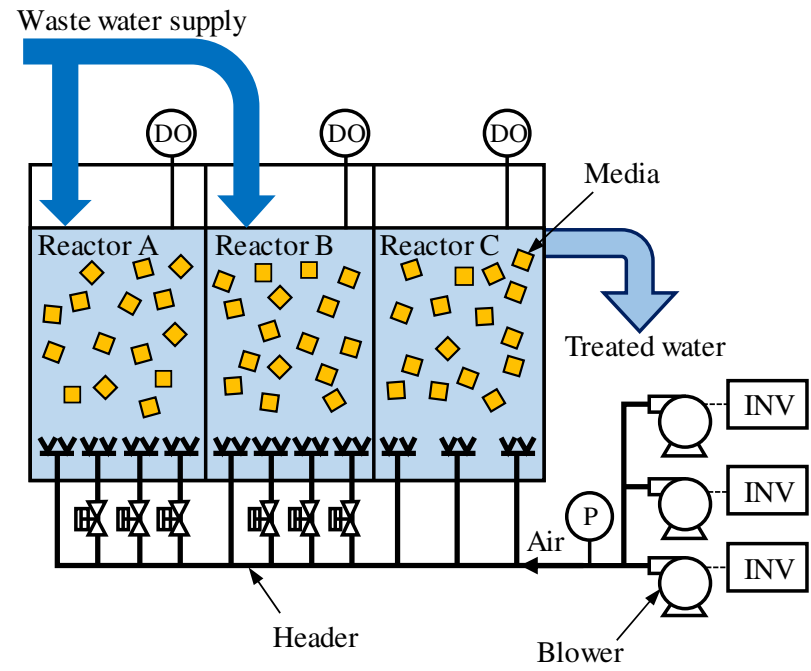

Figure 1. An example of an MBBR wastewater treatment system.
Figure 2 shows the MBBR process modeled by SUMO. This process consists of three reactors in series and each reactor model includes a layered onedimensional three-compartment model for the biofilm reactions with diffusion phenomena and a fully mixed balk water model for the outside of the biofilm. The number of state variables for this biological system was 1236. The detail of the base kinetic model was described by SumoSlang (Kovács et al., 2013). This model was exported as a DLL file. SUMO has Cinterface to SUMO solver which allows Modelica to control SUMO simulation through the External Object.

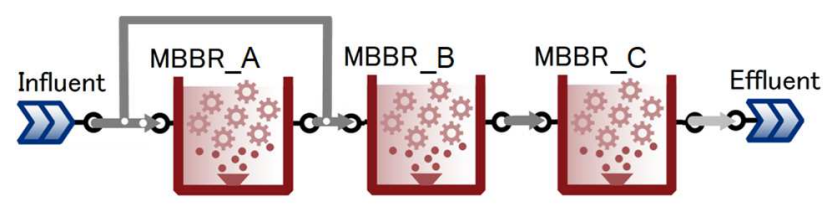

Figure 2. MBBR reactors modeled by SUMO.

\section{Framework for Simulator Coupling}

\subsection{Overview}

Modelica and SUMO simulate the mechanical component dynamics and biochemical process dynamics respectively, as shown in Figure 3. Modelica sets the load of wastewater and calculates the air flow rate to each reactor based on valve manipulation strategy for keeping DO constant combined with header pipe pressure control as previously described. SUMO estimates the water quality including DO based on given load and air flow rate provided by the Modelica model. Both simulator solvers use variable time step algorithms. Figure 4 shows a flow chart of the coupled simulation. The quasi-dynamic coupling method is used; each solver exchanges their simulation results before the beginning of each simulation step and uses the results of the previous time step. Therefore, the received data change discretely. A communication step size between Modelica and SUMO was determined as sufficiently shorter interval than the DO change response time to air

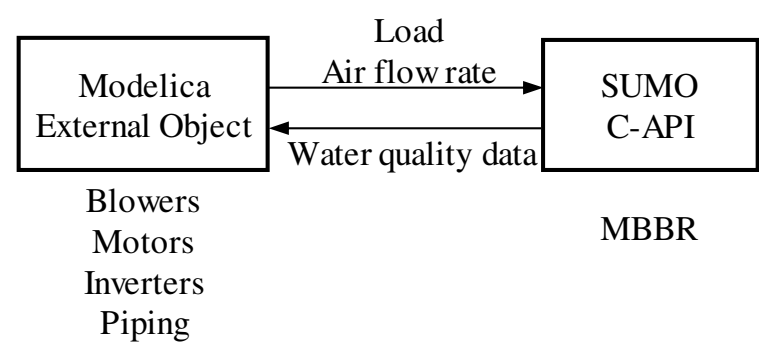

Figure 3. Simulator coupling. 


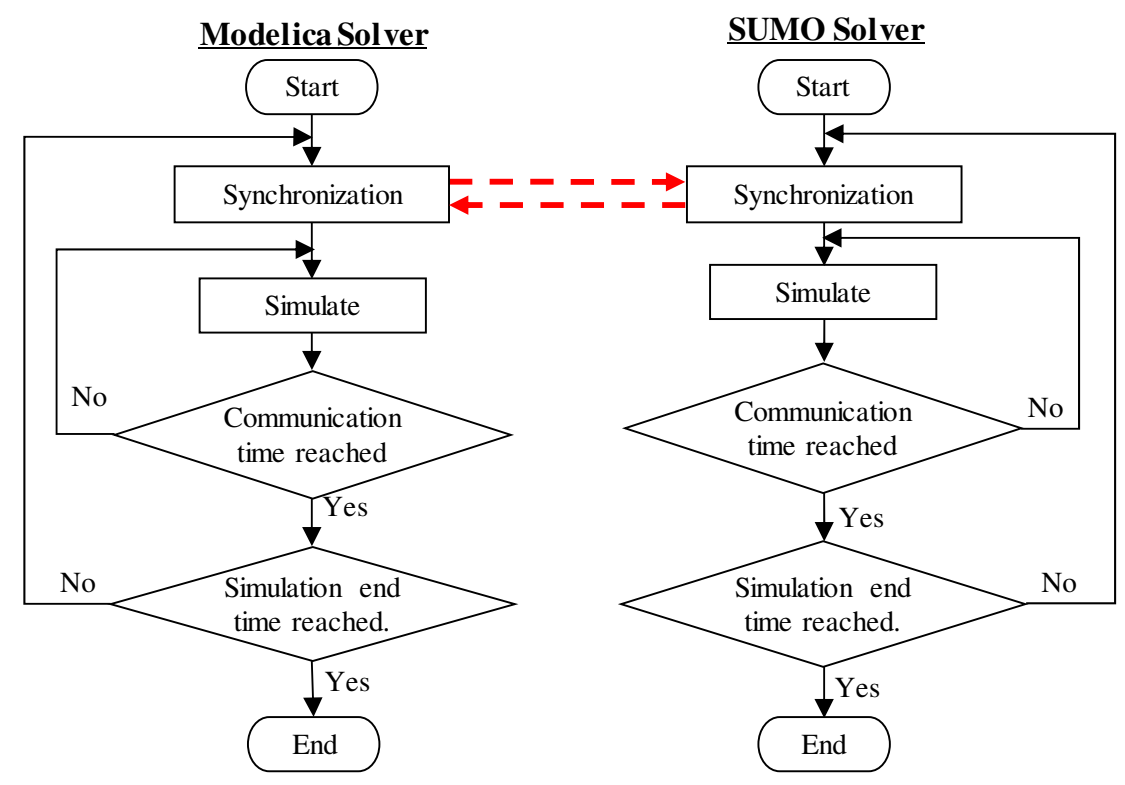

Figure 4. Flow chart of coupled simulation between Modelica and SUMO.

flow changes. Assuming oxygen transfer rate and DO sensor response time around several tens of seconds, 5 second communication interval is assumed to be sufficiently short. In biological wastewater treatment units, water quality other than DO has much longer time constants compared to this communication step size. It should be more than few minutes taking into account the hydraulic retention time calculated from rector size and influent flow rate which is typically more than hours. From this reason biological system can be assumed quite stable between these communication steps. Aeration system has much more shorter time constant than this communication interval in nature typically blower pressure control response time should be sub second order, which means mechanical models in Modelica need to take much shorter integration steps compared to SUMO biological process model in between the communication steps.

\subsection{Implementation in Modelica}

The coupling simulation framework described in the previous section was implemented as a Modelica model by using External Object. SUMO solver is started in a constructor, the process is initialized at the initialization process of Modelica, and the process of SUMO is destroyed by a destructor at the end of simulation.

Before the coupled simulation study is conducted, to commence the coupled simulation study under stable condition of biofilm states in MBBR which requires months of continuous operation, steady state of MBBR model is calculated by SUMO only unlinked with Modelica model exposing one year of constant wastewater load and aeration condition. After that, coupled simulation study with Modelica is conducted.

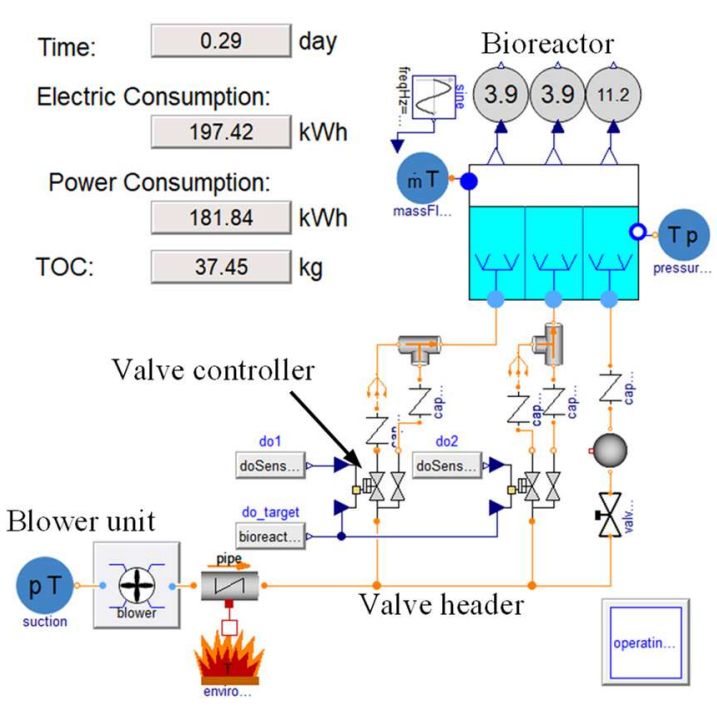

Figure 5. Biological wastewater treatment system simulator coupling implementation on Modelica.

The results of the biofilm initialization process can be exported from SUMO as an XML file which can be reloaded at the initialization step of coupled simulation study to shorten the initialization time.

\section{Simulation Results}

\subsection{System Model}

Figure 5 shows an MBBR wastewater treatment system modeled using Modelica. The components of the Modelon Base Library (MBL), which is a commercial library developed by Modelon, are used for the blower and piping components. The performance 
curves of the blowers, motors, and inverters are implemented in the corresponding component models to calculate a required shaft power and electric power consumption.

The TOC (total organic carbon) concentration of the influent wastewater is set in the water flow source by using the media ExtraProperty. The TOC represents the total concentration of the organic contaminants in the influents, and the SUMO model requires more detailed concentration profile information of these contaminants. Therefore, the fractional ratios of these contaminants in the TOC are set as the model parameters for the influent water. These ratio parameters are also specified by Modelica model and passed to the SUMO solver. Bioreactor model contains the External Oject to handle the SUMO solver.

This system model contains two on/off controllers for automatic valves, controller for aeration header pressure controller, and controller to manage the number of blowers on operation. Table 1 and Table 2 show the actions of the controllers. The valve controllers control the air flow rate to keep DO concentration of the reactor $\mathrm{A}$ and $\mathrm{B}$ based on the intermittent sampling of DO concentration. The blower speed is controlled to keep the header pressure constant. The air flow is estimated based on the $\mathrm{Cv}$ value settings of manual valves automatic on/off valves manipulated by control logic. These valves are connected in parallel, as shown in Figure 1. The number of blowers in operation is controlled based on the intermittent sampling of timeaveraged blower speed. If the averaged blower speed is low, that is the blower load is low, and if multiple blowers are running, the controller stops one blower.

\subsection{Case Study}

The system parameters of the target system are shown in Table 3. The TOC (total organic carbon) concentration of the influent wastewater was assumed to be constant, and flow rate and DO setpoint was assumed to follow sinusoidal pattern with a period of 1 day. Parameter study was conducted to evaluate the effect of different open/close action interval for the automatic valves.

Figure 6 shows the DO setpoint assumed, DO concentration estimated by SUMO and number of open valves of each reactor determined by controller. If the action interval is set to 1 minute or 2 minutes, DO concentrations were kept close to its target values. If the action interval is set to 5 minutes, DO concentration deviation from its target value became significant compared to other shorter interval cases. The action interval of 5 minutes was judged to be too long compared to the time constant of oxygen transfer process in the biological process.

Figure 7 shows TOC concentration of each reactor. The TOC concentration in the reactor A and B tended to increase when the influent load is increased. On the other hand, the TOC concentration of the last reactor $(\mathrm{C})$ is almost stable. There was no significant difference in these TOC concentration values between different automatic valve control intervals. The maximum TOC concentration values of effluent are $1.51 \mathrm{mgC} / \mathrm{L}, 1,46$ $\mathrm{mgC} / \mathrm{L}$, and $1.52 \mathrm{mgC} / \mathrm{L}$ for the interval of $1 \mathrm{~min} ., 2 . \mathrm{min}$ and 5 min., respectively. These values are essentially same as the values determined from the minimum achievable concentration assumed in the influent characteristic assumptions and the leakage of unbiodegradable matter from biomass through its decay process.

Table 1. Action of valve controller.

\begin{tabular}{|c|l|}
\hline DO concentration & \multicolumn{1}{c|}{ Controller Action } \\
\hline$>$ Target value & $\begin{array}{l}\text { Closes one opened valve. } \\
\text { If all on/off valves are open, } \\
\text { do nothing. }\end{array}$ \\
\hline$<$ Target value & $\begin{array}{l}\text { Opens one closed valve. } \\
\text { If all on/off valves are closed, } \\
\text { do nothing. }\end{array}$ \\
\hline
\end{tabular}

Table 2. Action of blower unit controller.

\begin{tabular}{|c|c|}
\hline $\begin{array}{c}\text { Averaged blower } \\
\text { speed (60min) }\end{array}$ & Controller Action \\
\hline < Low threshold & Stops one stopped blower. \\
\hline$>$ High threshold & Starts one running blower. \\
\hline
\end{tabular}

Table 3. Conditions for the case study.

\begin{tabular}{|c|c|}
\hline Model Parameters & Conditions \\
\hline $\begin{array}{c}\text { Influent wastewater TOC } \\
\text { concentration }\end{array}$ & $150 \mathrm{mgC} / \mathrm{L}$ \\
\hline Raw water flow rate & $\begin{array}{c}\text { Max: } 8.54 \mathrm{~m}^{3} / \mathrm{h} \\
\text { Min: } 2.56 \mathrm{~m}^{3} / \mathrm{h}\end{array}$ \\
\hline Number of reactors & 3 \\
\hline Volume of each tank & $400 \mathrm{~m}^{3}$ \\
\hline Number of blowers & 3 \\
\hline $\begin{array}{c}\text { Number of on/off valves } \\
\text { Header pressure }\end{array}$ & 3 \\
\hline $\begin{array}{c}\text { Sampling interval of } \\
\text { blower unit controller }\end{array}$ & $1.519 \mathrm{barA}$ \\
\hline $\begin{array}{c}\text { Open/close action interval } \\
\text { for the automatic valves }\end{array}$ & $\begin{array}{c}1 \mathrm{~min} . / 2 \mathrm{~min} . / 5 \\
\text { min. }\end{array}$ \\
\hline
\end{tabular}


The last reactor could be judged to be effective for the final polishing task as its designer expected. This also means aeration control setting does not have any effect on the effluent quality as far as we tested. We can focus on the energy efficiency and mechanical action difference in these cases. These effluent quality results

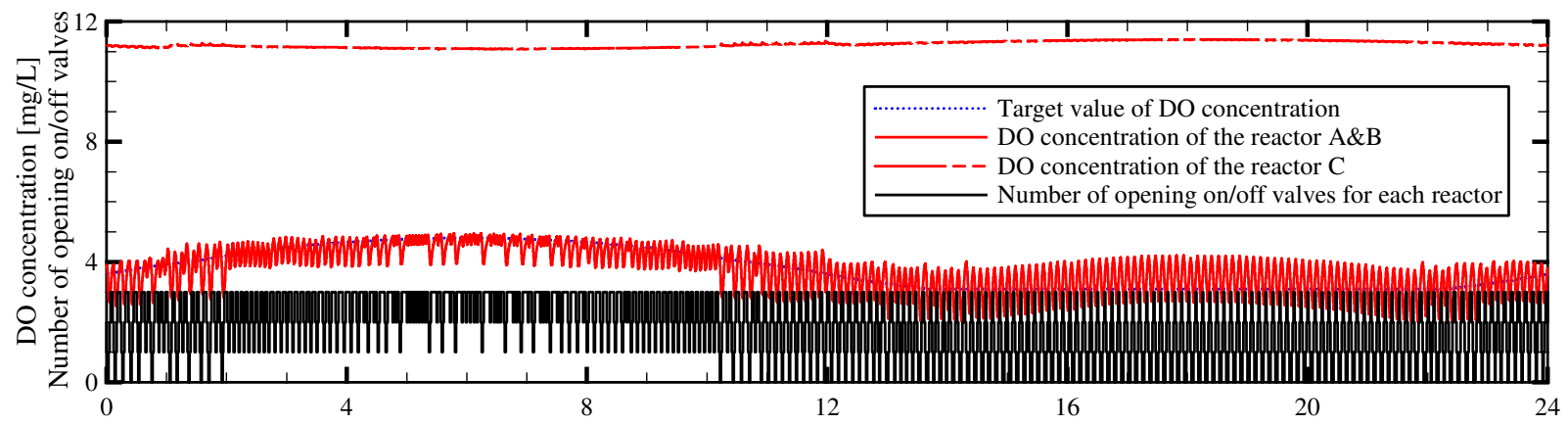

Time [hour]

(a) 1 minute.

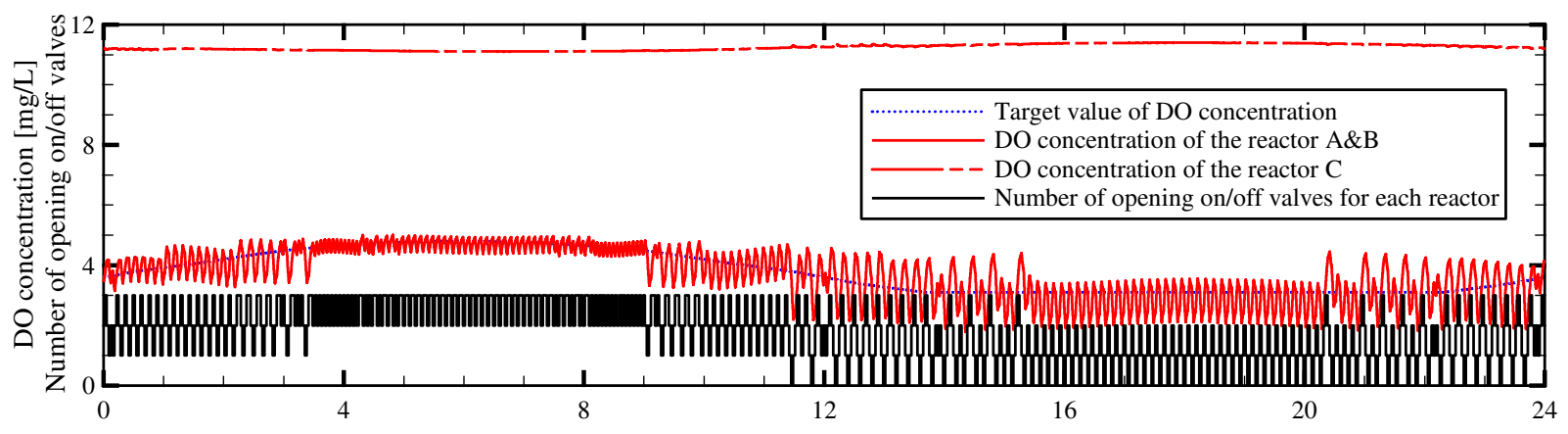

Time [hour]

(b) 2 minute.

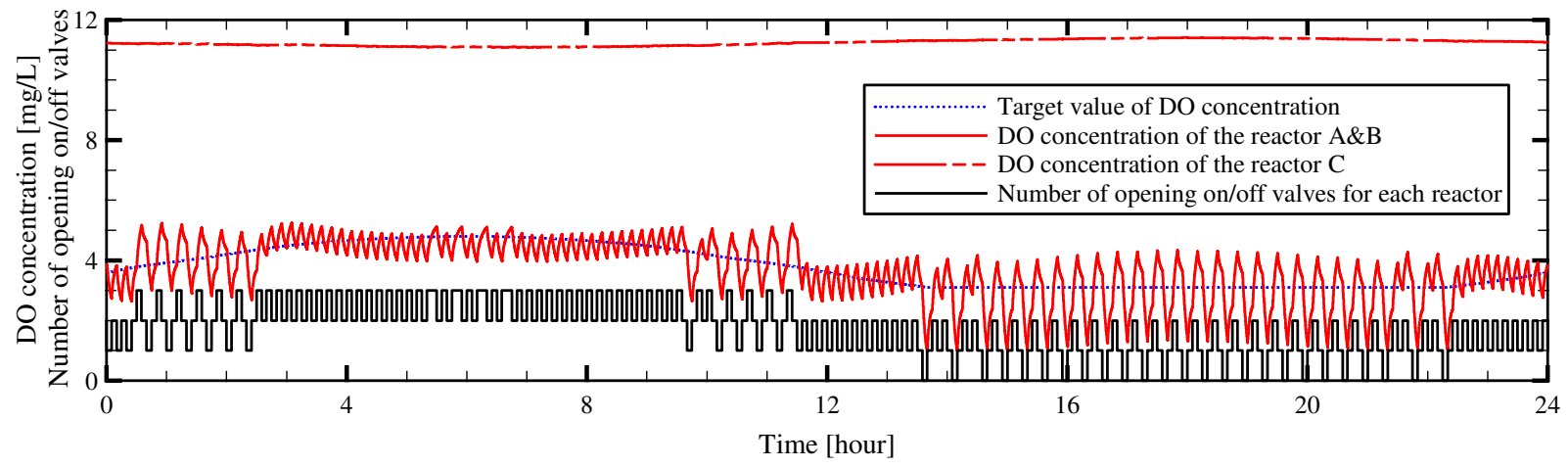

(c) 5 minute.

Figure 6. DO concentration and number of open valves of each reactor.

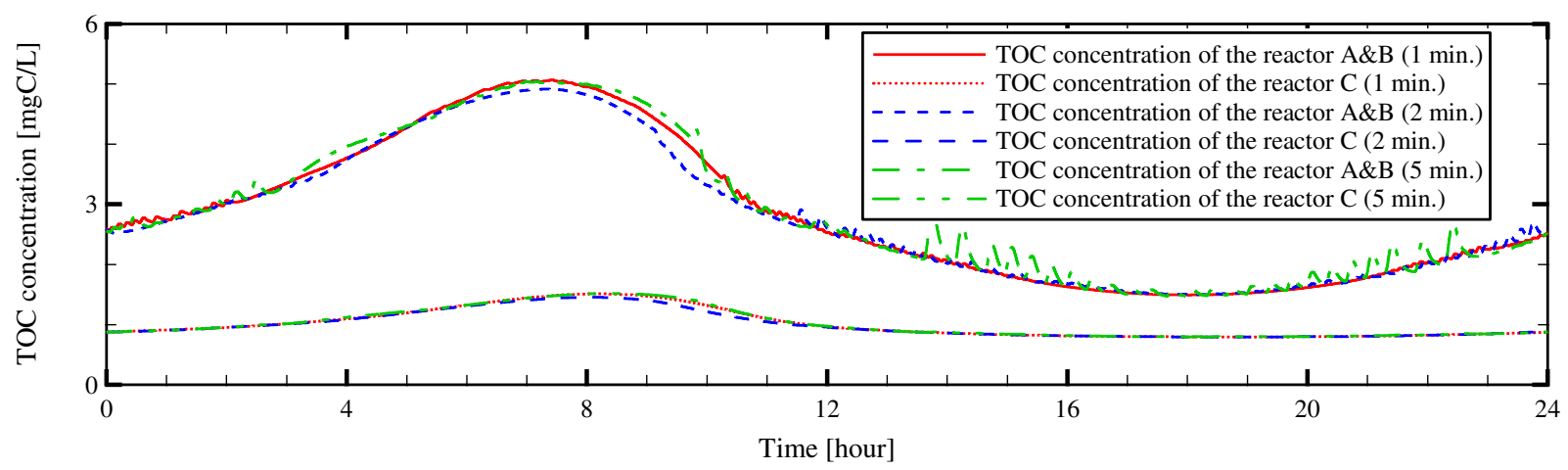

Figure 7. TOC concentration of each reactor. 


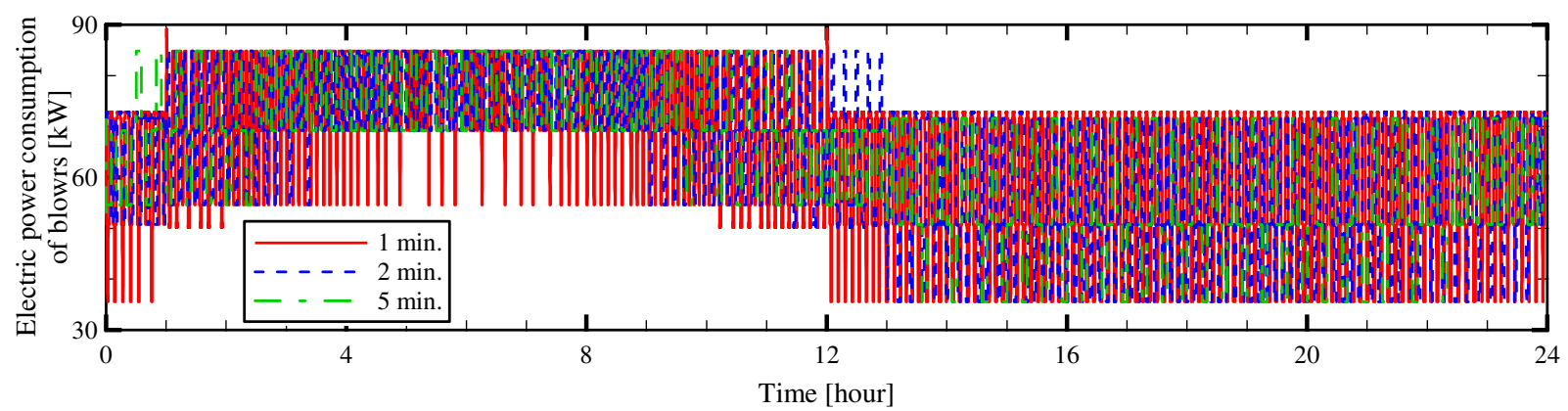

Figure 8. Electric power consumption of blowers.

of the simulation were obtained from a theoretical understanding of the process, and they were consistent with the observed TOC values of the effluent under the sufficient aeration intensity, ranging around 3 to 5 $\mathrm{mgC} / \mathrm{L}$.

Figure 8 shows the electric power consumptions of the system. The power consumptions are almost proportional to the number of open valves, or air flow rate. It is confirmed that the necessary air flow is almost determined by the load, and the effect of the valve on/off interval was negligible.

Total electric energy consumption and the number of times the valve opened are shown in Table 4. It is estimated that the total energy consumption is almost determined by the total amount of the load as is the case with the instantaneous value, and the electric energy consumption values for all cases are almost same. From the perspective of maintenance costs, a smaller number of valve openings is preferable in order to avoid unnecessary wear of the installed valves. In this aspect, 5 minutes interval is obviously preferred for the expected longer valve life. The simulator coupling could provide the designers with the information necessary to check expected water quality, power consumption, and equipment maintenance interval.

Table 4. Simulation results.

\begin{tabular}{|c|c|c|c|}
\hline & Imin. & 2 min. & 5 min. \\
\hline $\begin{array}{c}\text { Electric energy } \\
\text { Consumption }\end{array}$ & $\begin{array}{c}1557 \\
\mathrm{kWh}\end{array}$ & $\begin{array}{c}1554 \\
\mathrm{kWh}\end{array}$ & $\begin{array}{c}1542 \\
\mathrm{kWh}\end{array}$ \\
\hline $\begin{array}{c}\text { Number of times } \\
\text { the valve opened }\end{array}$ & 554 & 336 & 141 \\
\hline
\end{tabular}

\section{Conclusions}

In this report, the coupled simulation for the system analysis of wastewater treatment is demonstrated where water treatment process is simulated by domain- oriented simulator and the mechanical components related to aeration is simulated using Modelica via Dymola. These solvers are successfully linked through the C interface of SUMO and the Modelica External Object. The system level effect implication of the different aeration control scenarios can be investigated using the developed system model. Specifically, effect on the MBBR biological treatment process performance, the electric energy consumption of blowers and cycle frequency on the automatic valves can be evaluated. That is, it could provide the necessary information for water treatment performance evaluation, the operation cost and maintenance cost planning.

There are many domain-specific simulators which does not rely on Modelica and FMI technologies. But, Modelica tools can still be used under the simulator coupling framework developed if external simulators can provide a low-level manipulation interface such as a C language API. The authors expect the practical usefulness of the coupled simulation of domain-specific simulators and Modelica models, as shown in this paper, will be a driving force to promote the utilization of the wide range of existing models based on Modelica hopefully through the application of more convenient model integration methods such as FMI to the domain.

\section{References}

M. Henze, W. Gujer, T. Mino and M. v. Loosdrecht, 2000. Activated sludge models ASM1, ASM2, ASM2d and ASM3. IWA Publishing.

M. Henze, L. G. Jr., W. Gujer, G. v. R. Marais and T. Matsuo, 1987. Activated Sludge Model No.1. IAWPRC Publishing.

R. Kovács, I. Takács and J. D. Benke. Facilitating biofilm reactor modelling with an easy-to-use spreadsheet-based tool designed for process engineers. IWA Biofilm Conference, 2013.

G. G. Patry and D. T. Chapman, 1989. Dynamic Modeling and Expert Systems in Wastewater Engineering. Lewis Publishers, Inc.

G. Reichl. WasteWater a Library for Modelling and Simulation of Wastewater Treatment Plants in Modelica. 3rd International Modelica Conference: 171-176, 2003. 
L. Rieger, S. Gillot, G. Langergraber, T. Ohtsuki, A. Shaw, I. Tak'cs and S. Winkler, 2012. Guidelines for Using Activated Sludge Models. Scientific and Technical Report Series, 11. IWA Publishing.

D. L. Russell. Practical Wastewater Treatment, Second Edition. WILEY, pp. 264-265, 2019.

L. M. Sidek, H. A. Mohiyaden, G. Hayder, A. HusseinS, H. Basri, A. F. Sabri and M. N. Noh. Application of Moving Bed Biofilm Reactor (MBBR) and Integrated Fixed Activated Sludge (IFAS) for Biological River Water Purification System: A Short Review. IOP Conference Series Earth and Environmental Science, 2016.

M. V. Sperling and C. A. d. L. Chernicharo, 2005. Biological Wastewater Treatment in Warm Climate Regions Volume I. IWA Publishing. 